\title{
Structural Behavior of Steel-Concrete Composite Beam using Bolted Shear Connectors: A Review
}

\author{
Nadiah Loqman ${ }^{1, *}$, Nor Azizi Safiee ${ }^{1}$, Nabilah Abu Bakar ${ }^{1}$, and Noor Azline Mohd Nasir ${ }^{1}$ \\ ${ }^{1}$ Department of Civil Engineering, Faculty of Engineering, University Putra Malaysia 43400 UPM Serdang, Selangor, Malaysia
}

\begin{abstract}
Conventional steel-concrete composite beams have been recognized to exhibit stronger structural characteristics, in terms of strength and stiffness, when compared to pure steel or reinforced concrete beams. However, currently most steel beam is fully attached to the concrete slab; this means that the shear connectors are welded through the steel decking on to the steel beam and cast into concrete slab to fulfill the necessary shear connection. Recently, the deconstruction and reuse of the components almost impossible. In order to achieve a sustainable structural system, precast concrete slabs are attached to a steel beam using bolted shear connectors in prefabricated holes have been introduced as an alternative to the conventional connectors in steel - concrete composite beam system. This paper reviews the structural behavior of composite beam system such as the strength, stiffness, slip behavior, failure mode and sustainability obtained by experiment and numerical studies in order to address the applicability and efficiency of the composite beams having precast concrete slabs and bolted shear connectors.
\end{abstract}

\section{Introduction}

In many buildings and bridges, it is common to have a concrete slab supported by steel beams. If the steel beams are connected to the concrete slab by using various type of shear connectors that makes the two act as one unit, the beam is called as composite beam and it is getting more popular in modern structures [1]. This is due to their high strength-toweight ratio and their good corrosion properties compared to the individually steel element or traditional concrete elements. Moreover, they have an excellent structural performance in terms of stiffness, their simplicity of construction and the significant economic advantages that benefit to this structural form [2].

Composite beam is a combination construction of different type of materials but the most common use of the materials is when the concrete as a slab and steel as a beam in composite beam. Steel and concrete are very different in nature, but these two materials complement one another; concrete as a slab is efficient in compression and steel as beam is efficient in tension. In this case, the steel beam is subjected to tensile stresses and the concrete slab is primarily subjected to compressive stresses as shown in Fig. 1, thus utilizing the favourable attributes of each material in an efficient manner [3]. Steel components are relatively thin and prone to buckling while concrete can restrain these against buckling, concrete also gives protection against corrosion provides thermal insulation at high temperatures and steel provides ductility into the structure. A rigid-plastic analysis of a composite beam section indicates that the positive moment capacity of a member can be increased by as much as $120 \%$ relative to the bare steel beam through composite action [4]. Moreover, the common solid concrete slab with a depth of $75 \mathrm{~mm}$ to $100 \mathrm{~mm}$ thick provides lateral-torsional buckling resistance to the top flange [5].

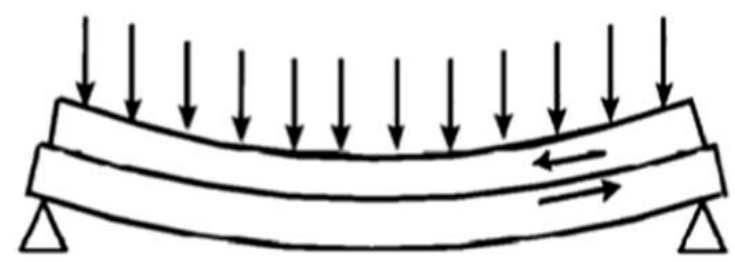

Fig. 1. Compression and tension direction in composite beam [3]

\footnotetext{
* Corresponding author: nadiahloqman@gmail.com
} 
A high strength composite beam is achieved due to higher stiffness and higher load resistance in comparison to noncomposite beam with an assumption that it is in infinite state that prevent any slip between two construction elements by shear connectors as shown in Fig. 2 [6].

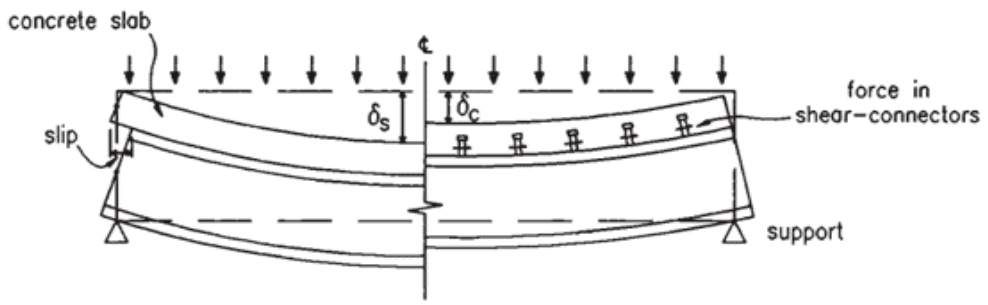

non-composite

beam

Fig. 2. Non-composite and composite beam [7]

The main role of shear connectors in composite beam is to transfer the longitudinal shear stresses at the interface between the steel beam and the concrete slab in order to obtain the composite beam behavior [8]. There are various types of shear connectors being used in composite beam such as headed stud, perfobond ribs, t-rib connector, oscillating perfobond strips, waveform strips, t-connectors, channel connector and non-welded connectors [9]. The most common solution to achieve the composite behavior is by using headed stud shear connectors. This is because, the composite action can be achieved almost perfectly by using headed stud shear connectors that are welded to the top flange of the steel beam and which are embedded in the cast in situ concrete slab [2]. In such composite beams, mechanical shear connectors are generally used to provide the essential shear transfer at the steel-concrete interface by connecting the concrete slab and the steel beam to ensure effective composite action. Headed stud shear connector is the most widely used mechanical shear connector (type (a) in Fig. 3), since this type of shear connector can provide robust and ductile shear connection and can be easily installed [10]. Other advantages that can be obtained by using headed stud connectors are; fast welding, good anchor in concrete, the arrangement of reinforcement through the slab is easy, production of large scale size is easy, the standard dimensioned head is a resistance factor for slab uplift and they are practical to be used in steel deck slabs.

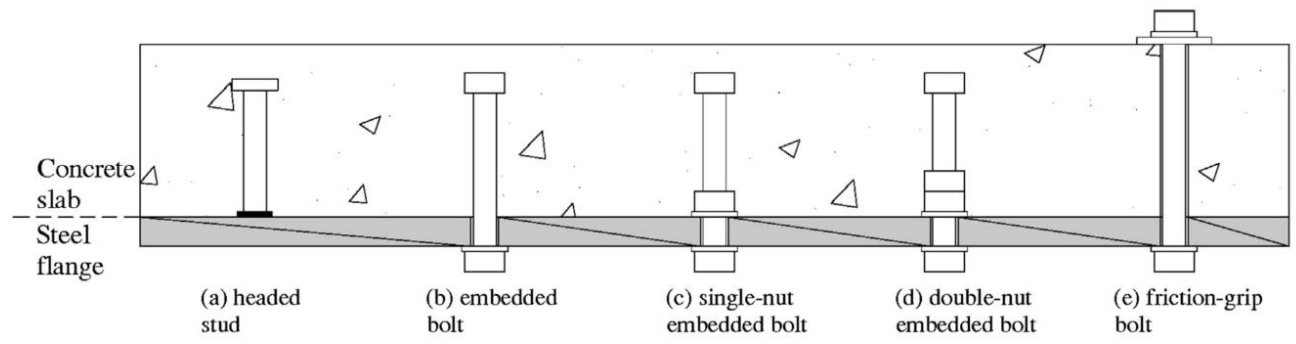

Fig. 3. Type of shear connectors [10]

However, many medium-rise buildings have relatively short structural lives in response to changes of urban land use and require demolition [11]. Some of the important issues related to sustainability and full life-cycle assessments in building construction and usage need to be concerned [10]. Conventional headed stud shear connectors that have to be welded to the flange of the steel beam section and cast into the concrete slab to achieve the necessary shear connection cannot be deconstructed easily and their elements are not recyclable. Moreover, their demolition is wasteful, energyintensive and environmentally-intrusive, with the reuse of the components being almost impossible. The conventional composite beam also which using in-situ casted concrete requires often temporary supports and formwork which leads to a longer construction time [12]. If the replacement of concrete slabs is required either for structural reasons (maintenance) or practical reasons (end of the life time), bolted shear connectors has big advantages as an alternative to replace headed stud shear connectors in composite beams because of easier dismantling [13]. Therefore, the usage of bolted shear connector in composite beam is increasingly demanded due to its sustainability issue and need to be particularly discussed in this paper.

This paper presents an overview of the developments in the category of 'bolted shear connector in composite beam', followed by an evaluation of the concepts. The paper focuses on both experimental and numerical studies. This is because, the experimental work is extremely important in this type of composite beam where their structural characteristics such as the strength, stiffness, slip behavior, failure mode and sustainability is measured in actual condition. However, it is stated that a significant amount of numerical and analytical investigations on this concept is also available for several of treated concepts. The parameters include the number of bolts, diameter of bolts, location of 
bolts, type of bolted shear connectors, concrete panel configuration, concrete strength and type of steel grade. In general, the paper summarized all the structural characteristics stated from the experimental approach and then proposed all the availability of different parameters to address the applicability and efficiency of the composite beams having bolted shear connectors.

\section{Types of bolted shear connectors}

Bolted shear connector is introduced in composite beam to cater the issue of sustainability of the construction. The advantages of bolted shear connectors are that they can be used to connect precast concrete slabs and steel girders during construction and they can be unbolted to deconstruct the building at the end of its service life and to recycle or reuse its components in preference to expensive and environmentally-disagreeable demolition [14]. The use of this type of shear connector can also be an effective approach for the rehabilitation and strengthening of existing non-composite structures such as bridges [15]. In the previous research, numerous researches on push-out tests and flexural composite beam tests have been conducted on various types of bolted shear connectors. In this paper, an attempt has been made to review the different types of bolted shear connector that can be found in composite beams such as high-strength friction-grip bolt, bolt without embedded nut, bolt with single embedded nut and bolt with double embedded nut as shown in Fig. 4 [12].

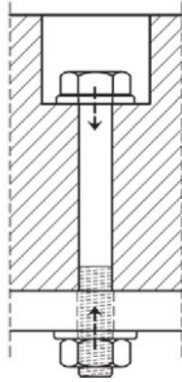

a) friction grip bolt

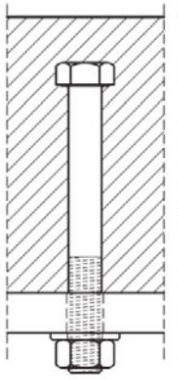

b) without embedded nut

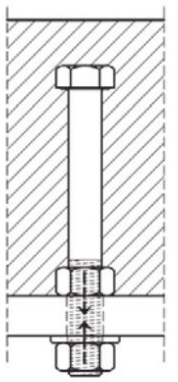

c) single

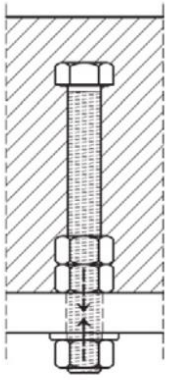

d) double

embedded nut

Fig. 4. Type of bolted of shear connectors [12]

\subsection{High-strength friction grip bolt}

Research on high-strength friction grip bolted shear connectors on steel-concrete composite beams appears to be first reported in 1968 by Dallam followed by Marshall et al. and Rabbat et al. through push-out tests evaluation [16-18]. Push-out tests utilizing various sizes of high-strength friction grip bolts as shear connectors were tested. In this test, the bolts were embedded in the concrete slab and post-tensioned by the turn-of-nut method after the concrete reached 28 days of compressive strength. Zero slip at the serviceability stage was resulted and higher load capacity than stud shear connectors. Subsequently, six full-scale simply supported composite beams on the usage of similar type of bolt were tested [19]. The bolts being embedded in the concrete slab in the same way as for push tests with the same diameter and height of the bolts. They noted that the high-strength bolted shear connectors give a very rigid connection between the steel beam and concrete slab under service loads with high level of composite efficiency, and attained a reserve capacity sufficient for the development of the ultimate moment of the fully composite section.

In 2014, Chen et al. performed a static push tests on through-bolt shear connectors with the idea to enhance the contact surface friction properties between the steel girders and the precast concrete deck panels for accelerated bridge construction [20]. The research intended to develop a comprehensive design rules for ultimate and fatigue limit state verification that was not cover in the previous study. However, the result indicated a low initial slip load which means low contact surface friction properties between steel and concrete, but a ductility and peak load comparable to that of a conventional shear stud. Thus, the effort taken to increase the slip load was not successful.

In 2015, an experimental study of composite beams having precast geopolymer concrete slabs that are attached to a steel beam using tensioned high-strength friction-grip bolts in clearance holes as shear connector were carried out and reported by Ataei et al. [2]. In this study, four full-scale composite beams were tested under quasi-static tests as shown in Fig. 5. The result concluded that composite beams with tensioned friction-grip bolted shear connectors are very ductile when compared with conventional composite beams with headed stud shear connectors. At the end of the experiment, the composite beams with geopolymer concrete panels that are attached to the steel beam with tensioned high-strength friction-grip bolts in clearance holes can be deconstructed successfully when loaded into the service load range, and the components are able to be reused. 


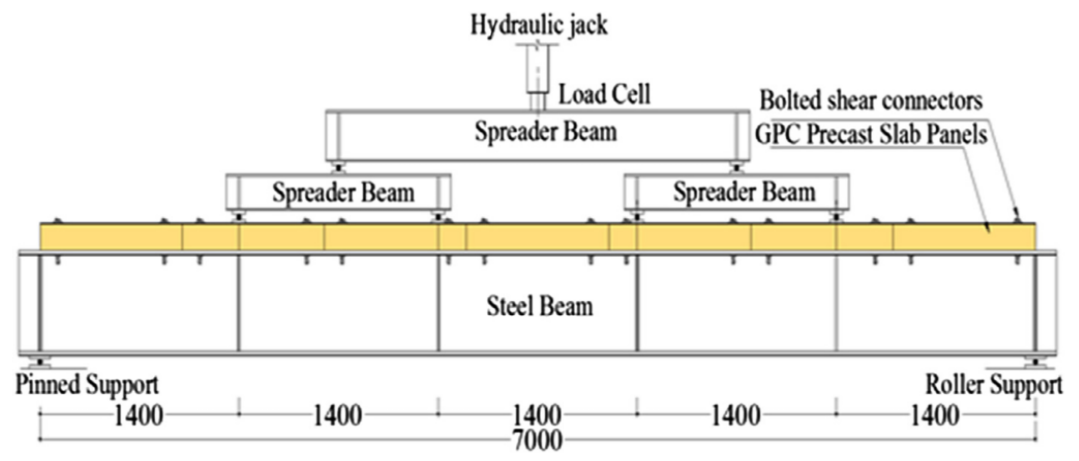

Fig. 5. Configuration of test set-up [2]

Although, the push-out tests was already being conducted experimentally by previous research, the result was not satisfy enough to develop a comprehensive design rules for composite beams using high-strength friction grip bolt (HSFGB) shear connectors. Therefore, Liu et al. conducted an accurate and efficient three-dimensional (3D) finite element model to investigate the behavior of HSFGB shear connectors in composite beams with precast geopolymer concrete slabs [21]. Based on the result, they explained about the load-slip response of the HSFGB shear connectors that exhibited into three distinct regimes. At the early stage of loading, almost zero slip due to pretension connection. Then, a significant slip took place resulting from the clearance between the prefabricated holes and the bolts after the friction at the steel-concrete interface induced by the pretension of the shear connection was overcome. A third regime for the behavior developed after the bolt commenced to bear against the surface of the hole in the slab.

\subsection{Bolt without embedded nut or anchor bolt}

Bolt without embedded nut was first introduced by Hawkins where he performed a large experimental research on anchor bolts or bolt without the embedded nut in shear and tension [22]. Variables for shear tests were the anchor bolt diameter (19 and $25 \mathrm{~mm})$, embedment length $(76,127$ and $178 \mathrm{~mm})$ and concrete strength $(20.7 \mathrm{and} 34.5 \mathrm{MPa})$. He showed that such anchors have $80 \%$ shear resistance when compared to welded headed studs and only $15 \%$ of shear stiffness. Therefore, it is concluded that ductility of bolted shear connectors without embedded nut is higher, but the stiffness and shear resistance of such shear connector is remarkably reduced when compared to welded headed studs.

In order to improve the problem in terms of stiffness and shear resistance reported by Hawkins, Kwon et al. introduced an adhesive anchor (HASAA) in the composite beam [23]. In this study, the 22 mm adhesive anchor is installed after an adhesive was injected in a $24 \mathrm{~mm}$ predrilled hole. The results showed consistent behavior under static loading and a higher load ratio (load at $5 \mathrm{~mm}$ slip/Max. load) when using the HASAA connector compared to other type of bolted shear connectors. This may due to low oversized hole in the concrete block and in the steel plate for the shear connector that could reduce the strength at low slip levels.

\subsection{Single-nut embedded bolt}

Besides high-strength friction-grip bolt and bolt without embedded nut, single-nut embedded bolt also gained attention from a number of researchers by its improvement in terms of structural behavior [12,24,25]. Dedic and Klaiber was the first to introduce a single embedded nut as bolted shear connector in composite beam for rehabilitation work [24]. Four experiments were carried out on $19 \mathrm{~mm}$ ASTM A325 high-strength bolts, without or with single embedded nut. The existing composite bridge girders were retrofitted by post-tensioning, thus, the bolts were post installed to increase the shear strength of the steel-concrete interface. The result showed that the shear resistance load-slip behavior of bolted shear connectors are comparable to welded headed studs of the same dimensions. However, the study only focused on retrofitting existing composite bridge girders by post-tensioning. The structural behavior of bolted shear connectors for prefabricated concrete composite beam was not investigated.

In order to gain a better understanding of failure modes of single-nut embedded bolt, Pavlovic et al. performed an experimental push-out tests and Finite Element (FE) analysis as the first step towards the design recommendations for bolted shear connectors for modern buildings [12]. They used $16 \mathrm{~mm}$ diameter single-nut embedded bolts as composite connectors in the push-out tests experiments as shown in Fig. 6. The experimental results showed that bolted shear connectors with single embedded nut (grade 8.8) achieve approximately 95\% of shear resistance for static loads of traditional arc welded headed studs shear connectors. However, due to the slip hole, threads-to-hole penetration and larger contribution of the shear force to the failure, the stiffness of single shear connector at serviceability loads is reduced to $50 \%$ for bolts when compared to headed studs. Based on the numerical results, the dominant failure mode of this type of bolted shear connectors is shear at interface layer through threaded part of a bolt with $67 \%$ participation of 
shear in multiple failure criterion compared to headed studs where the failure is governed by interaction of $56 \%$ bending and $37 \%$ shear in shank zone above the welded collar.
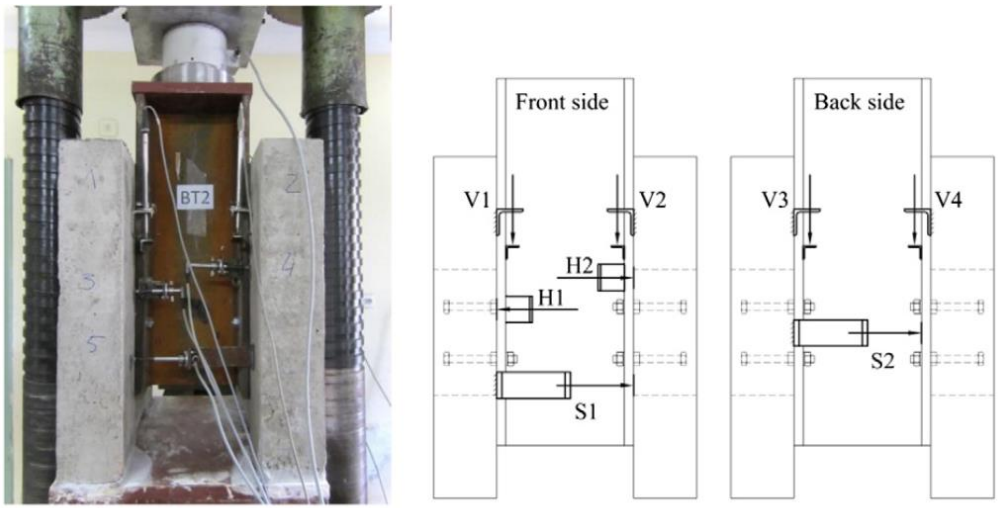

Fig. 6. Push-out test [12]

Another push out test has been investigated by Pavlovic on $16 \mathrm{~mm}$ diameter single embedded with the aim to improve the competitiveness of bolted shear connectors by focusing in detail with initial slip in hole of a bolted shear connector from prefabrication and cyclic loading point of view [25]. The result stated that 95\% shear resistance achieved by bolted shear connectors when compared to headed studs. However, brittle is showed in bolted shear connectors, while headed studs showed ductile behavior. The initial accumulated slip during cyclic loading in bolted shear connector is noticeable (from $0.4 \mathrm{~mm}$ to $1.5 \mathrm{~mm}$ ) due to existence of clearance between the bolt and the hole in steel flange while no initial slip in welded headed stud since they are welded to the steel flange. Also, due to penetration of bolt treads into the hole surface, the initial slips for bolted shear connectors are up to $50 \%$ higher than initial clearances ( $1 \mathrm{~mm}$ clearance in this study).

\subsection{Bolt with double embedded nut}

Bolt with double embedded nut generally gives higher stiffness than the other type of bolted shear connectors due large bearing area of embedded nut. Despite this, studies of the behavior of bolt with double embedded nut shear connectors in composite beams are quite limited compared to other bolted shear connectors. A study presented by Kwon et al. about the behavior of bolt with double embedded nut under static and fatigue loading [23]. In this study, the double nut is installed above the steel plate to reinforce the connector in this region and to help prevent connector rotation while the nut is tightened from the bottom side of the steel flange. Static and fatigue tests were carried out on a single shear connector using the direct-shear test as shown in Fig. 7. Based on the static test results, the composite beam with this type of shear connectors showed high stiffness in the elastic range due to an increase of the bearing surface between the connector and the concrete. This also help to delay concrete crushing in front of the shear connector. Moreover, a much higher fatigue strength is achieved compared to conventional welded shear studs.

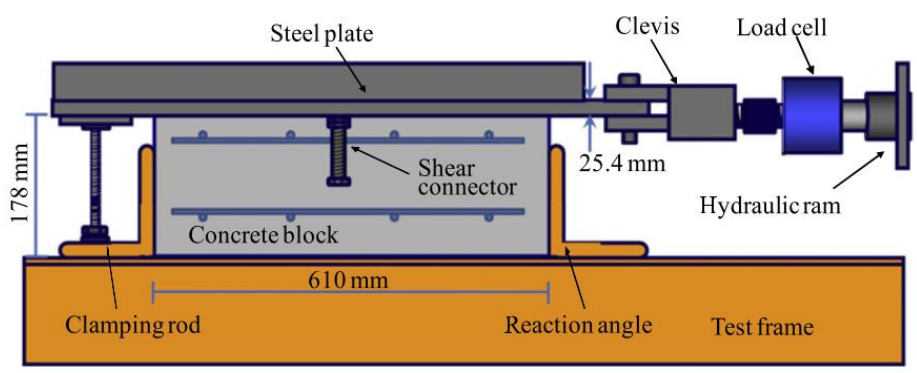

Fig. 7. Direct-shear test setup for single shear connector tests [23] 


\subsection{Others}

Apart from the four main bolted shear connectors being introduced in the previous sections, blind-bolts is also another type of bolted shear connector that can be used to strengthen existing composite steel-concrete beams more efficiently and effectively than welded stud connectors (see Fig. 8 and Fig. 9). In addition, the ability of being attached and detached from one side of a structure is one of the main advantages of these bolting systems that can be exploited to retrofit composite beams. In 2015, Pathirana et al. studied about the flexural behavior of steel-concrete composite beams retrofitted with bolted shear connectors by using blind-bolt as shear connectors [26]. A static flexural loading were tested on three retrofitted beams, three normal composite beams, and one non-composite beam. It is stated that the bolted shear connectors demonstrated much higher shear capacity than welded stud connectors in both the normal and retrofitted conditions. Moreover, the ultimate load capacity of the retrofitted beams with bolted shear connectors was much higher than that with the welded stud shear connectors.

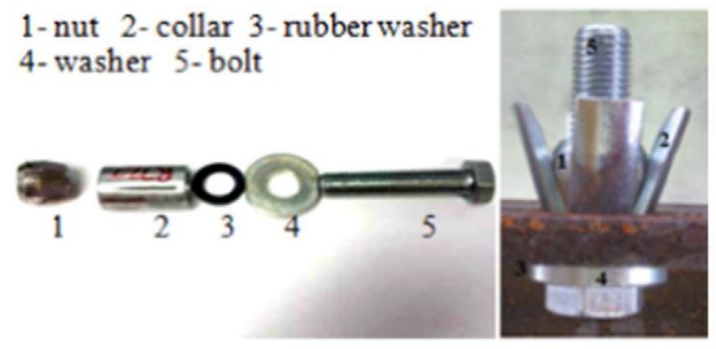

Fig. 8. Blind bolt $1[26]$

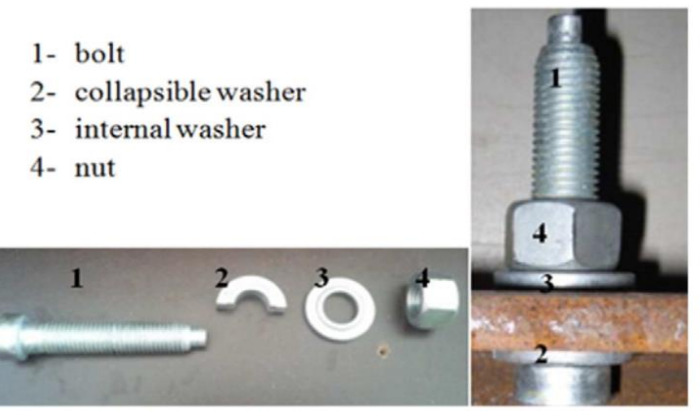

Fig. 9. Blind bolt 2 [26]

Recently, Wang studied about deconstructable composite beams by using $20 \mathrm{~mm}$ and $24 \mathrm{~mm}$ diameter bolts with clamped connections as shown in Fig. 10 [27]. Push out tests were conducted to document the load-slip curves of the clamped connections. The result on the load-slip curves indicated that the deconstructable clamping connectors using 24 $\mathrm{mm}$ bolts are ductile and retained almost $80 \%$ of the peak load at a slip of $5 \mathrm{in}$. in the monotonic test while the traditional shear studs fracture at a much less slip.

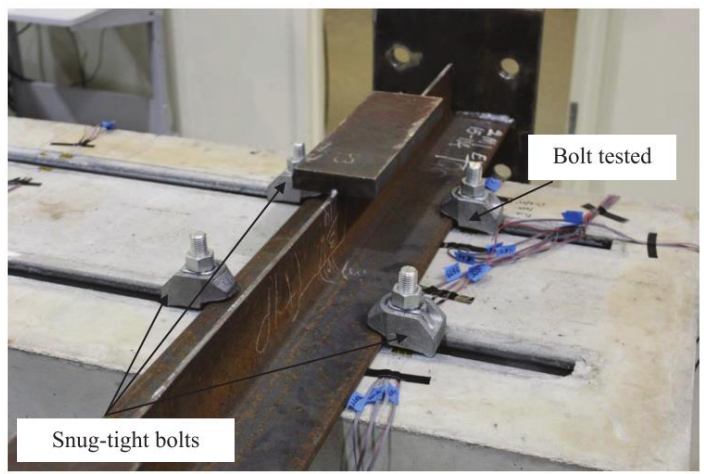

Fig. 10. Pretension test set-up [27] 


\section{Parametric studies by Finite Element Modelling (FEM)}

There are many factors that might affect the behavior of composite beam with bolted shear connectors. These include the shear connector types, shear connection ratio, bolt diameter, location of shear connectors, concrete panel configuration and concrete strength and grout. Thus, there a few studies have been carried out by using the developed Finite Element analysis to assess the effect of the parameters on the behavior of sustainable composite beam.

\subsection{Effect of different types of post-installed shear connectors}

There are various types of post-installed shear connectors being investigated but only three types of post-installed connectors is chosen by Kwon et al.; Double-Nut Bolt (DBLNB), High-Tension Friction-Grip Bolt (HTFGB) and Adhesive Anchor (HASAA) which shows strength levels that are greater than those of conventional welded studs $[15,23,28-30]$. Static push tests on these post-installed connectors showed significantly better strength capacity than conventional welded studs. The excellent strength performance of these three post- installed shear connectors is attributed, in large part, to the fact that no welds are involved in their installation. In terms of stiffness, HTFGB connector showed the highest initial stiffness with almost zero slip at the early stages of loading. This is because, the HTFGB connector initially transfers shear at the steel-concrete interface by friction. Thus, by using HTFGB connector, a composite beam can achieve full composite action without any slip at the steel-concrete interface before friction is overcome. HTFGB also showed a significant larger slip capacity than the DBLNB and HASAA connectors due to an oversized hole that provides larger slip capacity of the HTFGB connector. This enabled a greater degree of load redistribution among the shear connectors which results in higher strength and deformation capacity of this beam. Apart from that, the DBLNB connector specimens showed less concrete crushing than HTFGB and HASAA connectors, this may due to the large bearing area of nuts embedded in the concrete block. However, specimens with the DBLNB and HASAA shear connectors exhibited less overall ductility than the specimen with the HTFGB connector. Therefore, it is concluded that the HTFGB has more advantages than the DBLNB and HASAA.

\subsection{Effect of bolt spacing, number of bolts (shear connection ratio) and diameter of bolts}

Shear connection ratio of a composite beam depends on the number of connectors in the beam. A full shear connection in steel-concrete composite beam is recommended by most of the researches as it will gives higher ultimate strengths than partial shear connection [31-36]. This also proved by Kwon et al. that the strength, stiffness, and deformation capacity of the composite beams increased with increasing shear-connection ratio [29]. However, in comparison to different degree of shear connection with different diameter of bolts, the result is not very significant. For example, a study conducted by Liu et al. stated that a beam with a bolt diameter of $20 \mathrm{~mm}$ with a degree of shear connection ratio of 0.92 have similar ultimate strength with a bolt diameter of $16 \mathrm{~mm}$ with a degree of shear connection ratio of 0.85 [10]. Based on this finding, the construction costs can be optimized by using smaller size of bolt.

In terms of failure modes, Chen et al. reported a study on four different bolt spacing; $300 \mathrm{~mm}, 600 \mathrm{~mm}, 900 \mathrm{~mm}$ and $1200 \mathrm{~mm}$ [20]. In this study, the failure mode switches from concrete crushing or steel yielding to shear failure of bolted shear connector when the spacing increased to $600 \mathrm{~mm}$, and become more critical shear failure at $900 \mathrm{~mm}$. This means, the connectors already reach the peak shear before concrete slab crushing or steel yielding occur. Thus, it can be concluded that the stiffness of composite beam gradually decreases and vertical displacement at the midspan increases as the bolt spacing is increased.

If a partial shear connection ratio is used to minimize to construction costs, then it must ensure that a higher ultimate strength can achieved. A study conducted by Kwon et al. for retrofitting of existing non-composite steel bridge girders using post-installed shear connectors shows that all composite beams modeled in ABAQUS with shear connection ratios exceeding 30\% showed ductility factors higher than 2 [29]. They also agreed that at $30 \%$ shear connection ratio, the ultimate strength of the composite beam is almost $90 \%$ of the full degree of shear connection ratio which demonstrates an efficient use of partially composite beam. Moreover, the used of partial shear connection in composite beam enables initial stiffness close to those with full degree of shear connection. Thus, a minimum shear-connection ratio of $30 \%$ is recommended for retrofitting of existing non-composite steel bridge girders using post-installed shear connectors and also can be used in prefabricating new composite beams.

\subsection{Effect of locating shear connectors near supports}

At partial shear connection ratio, the location of shear connectors is an important parameter to be investigated. Oehlers and Sved stated that when the beam reaches its full flexural capacity, the slip at the steel-concrete interface can be reduced at concentrating shear connectors near zero-moment regions [35]. This is because simply supported beams with shear connectors concentrated near the supports can likely show higher deformation capacity than beams with uniformly distributed shear connectors along the span. Therefore, it is suggested that shear connectors are to be installed only near the supports or zero-moment regions for partial shear connection to increase the slip resistance [15].

A finite-element model for the beam with shear connectors concentrated near the supports showed significantly less slip at the steel-concrete interface. The load-deflection curve as shown in Fig. 11 showed a significant increase of the 
deformation capacity of the partially composite beam with shear connectors concentrated near the supports compared to uniformly distributed shear connectors. This indicates that the composite beam with shear connectors concentrated near the supports can deflect more than the beam with uniformly distributed shear connectors before any shear connector fails. Thus, rather than being distributed uniformly along the length of a beam, it is recommended that post-installed shear connectors be concentrated near zero-moment regions as it will increase the overall ductility of the strengthened partially composite beams and increase the slip resistance.

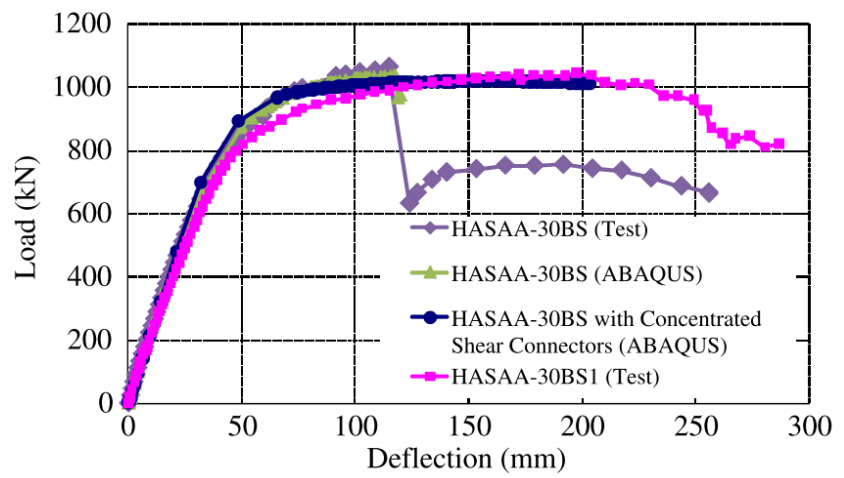

Fig. 11. Load-deflection relations for the composite beam with concentrated shear connectors [15]

\subsection{Effect of concrete panel configuration}

In designing composite beam with bolted shear connector, a precast concrete slab is incorporated because the elements are manufactured in a control casting environment and thus quality can be controlled and maintained easily compared to cast-in-situ concrete. The important parameter related to the concrete panel configuration is the width of the gap between the concrete panels. A finite element modelling has been conducted with the width of the gap between concrete panels varying from $0 \mathrm{~mm}$ to $4 \mathrm{~mm}$ [10]. Based on the result as shown in Fig. 12, it is showed that the beam behaves fully composite at the initial loading when the width of the gap between the concrete panels is zero. When the gaps are introduced between the concrete panels, it will reduce the initial stiffness of the beams dramatically. Therefore, it is suggested that the gaps between the precast concrete panels must be avoided during the beams assembly or grouting the gaps in the construction in order to achieve a sustainable concrete beams. This is because, the composite beam will functions in the same way as the steel joist alone at the early stage of loading and zero gaps width between the precast concrete panels will make the beam behaves fully compositely at the initial loading.

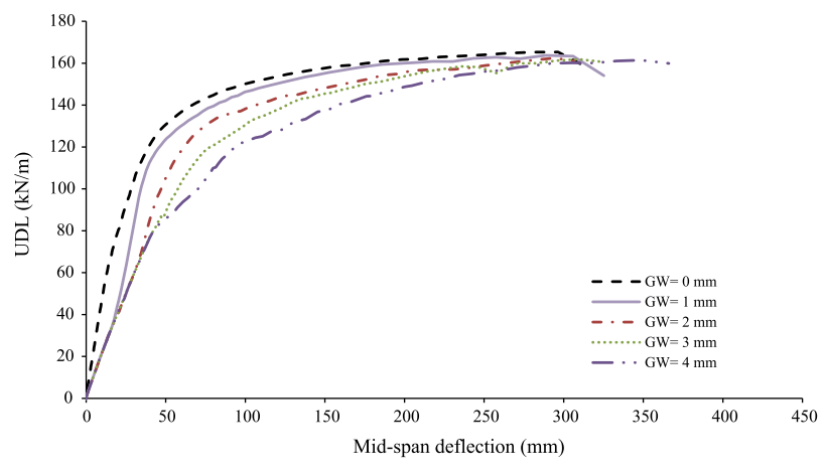

Fig. 12. Variation of load deflection curves with different gaps between the concrete panels [10]

\subsection{Effect of concrete strength and grout}

Concrete strength and grout in precast concrete slab is one of the important parameters to be considered in designing the composite beam. It is proved by most of the researches that as the compressive strengths of concrete increases, the ultimate strengths of composite beams increase, but not remarkably so [10,26,37,38]. For example, a study conducted by Liu et al. stated that when the concrete strength increases from 42 to $70 \mathrm{MPa}$, the ultimate strength of the beam increases by only $5 \%[10]$. However, it is stated that the shear resistance is dominate by the concrete crushing and 
splitting for lower slab concrete grade (less than C30) while the shear capacity is dominated by the shear stud strength for higher slab concrete grade [38]. Thus, a higher concrete strength is preferred in designing the composite beam.

In composite beam, the grout is used to cover the shear connectors inside the concrete slab. Based on the previous study, it is stated that the concrete grout with similar compressive strength as the concrete compressive strength did not have any substantial effect on the ultimate strength of the composite beam [10,26,37]. However, if the grout strength is lower than the strength of shear connector, then the grout in front of the connectors can experience high crushing strains during loading. A study from Pathirana et al. shows that the grout was severely damaged with more cracks appearing on the existing material compared with the damage of the concrete [26]. Therefore, a higher strength of concrete grout would be desirable to increase the strength of composite beam.

\section{Discussion}

The main purpose of introducing bolted shear connector in composite system is to expedite deconstructability within a paradigm of infrastructure sustainability. In contrast with headed stud connector where the connectors are welded onto the steel flange, bolted shear connector is deconstructable at the end of its service life through unbolting of the shear connectors. A study have proved that when the a composite beam with bolted shear connectors have been subjected to load within the serviceability range, they can be dismantled easily and all components of the composite system (the steel beam, bolts, nuts and concrete panels) can be reused without wasteful and environmentally-intrusive demolition processes [2]. This could contribute to a sustainable development and construction of composite beam system.

Overall, studies indicated that the implementation of bolted shear connectors in the composite beam system can achieved $95 \%$ of shear resistance under static loads when compared to headed stud shear connectors. Although the shear resistance of bolted shear connectors cannot overcome the shear resistance of headed stud shear connectors, it has a significant higher fatigue strength than the composite beam with headed stud shear connectors which is important for bridge strengthening.

There are three regimes of composite behavior with bolted shear connectors in terms of end slip that can be identified when the load applied. At the early stage of loading, the slip almost vanished. This is because of the pretension mechanism of the bolt which is due to the tightening of nut. At this moment, the interface friction and bond resist the loading. The second regime is categorized by a sudden slip of around $1 \mathrm{~mm}$, which is around the deformation allowed in the clearance between the prefabricated holes and the bolts. Then, a third regime for the behavior developed after the bolt commenced to bear against the surface of the hole in the slab. Although, the composite beam with headed stud shear connectors showed a much higher initial stiffness compared to the composite beam with bolted shear connectors, it experienced sudden a zero interaction between the concrete slab and steel beam after the strength of the connectors was overcame. This shows that the composite beam with bolted shear connectors are much more ductile than that with the headed stud shear connectors in regard to end slip. Further investigation of the ductility and influence of initial slip in hole to the overall behavior of prefabricated composite beam would be necessary for promotion of the prefabricated composite beam construction.

In terms of failure mode of composite beam with bolted shear connectors, most of the composite beam tested for flexural test failed due to concrete crushing by a huge deflection when the maximum load capacity is reached. This means that the bolted shear connector does not reached its ultimate shear strength when the composite beam failed. Therefore, it is recommended to use a higher concrete strength and grout in precast concrete slab.

\section{Conclusion}

The structural behavior of the composite beam system such as the strength, stiffness, slip behavior, failure mode and sustainability obtained by experiment and numerical studies in order to address the applicability and efficiency of the composite beams having precast concrete slabs and bolted shear connectors is already reviewed in this paper. Based on previous studies, some important parameters should be highlighted for future study. Firstly, the used of High-Tension Friction-Grip Bolt (HTFGB) in composite beam should be recommended for future study as it can gives a higher overall performances than the other type of bolted shear connectors. Based on push-out test results, Liu et al. [21] proposed that the ultimate strength of HTFGB shear connectors $Q_{u}$ in steel-concrete composite beams could be obtained from

$$
Q_{u}=0.66 A_{s c} F_{u}(N)
$$

where $A_{s c}$ is the cross-sectional area of the shear connector in $\mathrm{mm}^{2}$ and $F_{u}$ is the tensile strength of the high strength bolt shear connector in MPa. The flexural strength of composite beams can be obtained from equilibrium of the forces by assuming full yielding of the steel beam and an equivalent rectangular stress block in the concrete slab, and considering the longitudinal shear strength of the shear connection in a shear span.

Secondly, further efforts to increase the initial slip loads for HTFGB could lead to significant benefits for this connection type. It is hypothesized that a more uniform roughness and a better roughness match between the two sides of the contact surface would be needed for the contact surface modification to result in a significant increase in the slip load. There are three distinct regimes of the load-slip response that will be taken into consideration which has been 
discussed in the discussion section. The first significant slip occurs after the friction at the steel-concrete interface from the pretension of the shear connectors is overcome at shear force $Q_{o}$ that is given by

$$
Q_{o}=\mu_{f} k_{h} N_{t}
$$

where $\mu_{\mathrm{f}}$ is the coefficient of friction between the precast concrete slab and the steel beam and $N_{t}$ is the bolt tension. The factor $k_{h}$ is normally taken as 1.0 that allows for the shape and size of the hole in relation to the bolt. The corresponding load can be obtained from

$$
Q_{1}=Q_{o}+20 k N
$$

The empirical formula is proposed for the third regime which is after the bolt bears against the steel and concrete, the equation is given by

$$
Q_{s h}\left(\Delta_{\text {slip }}\right)=Q_{1}+\left(Q_{u}-Q_{1}\right)\left\{1-\exp \left[-0.005 f_{c k}\left(\Delta_{\text {slip }}-\Delta_{1}\right)\right]\right\}^{0.8}
$$

where $Q_{s h}$ is the applied shear force in shear connector $(\mathrm{N}), \Delta_{\text {slip }}$ is the slip of shear connector in mm, $f_{c k}$ is the compressive strength of the precast concrete slab and $\Delta_{1}$ is the critical slip which is given by

$$
\Delta_{1}=\left(d_{c}+d_{s}-2 d_{b}\right) / 2
$$

for which $d_{c}$ is the diameter of the hole in the concrete slab, $d_{s}$ is the diameter of the hole in the steel beam flange and $d_{b}$ is the diameter of the bolt. Fig. 13 shows the load and slip displacement relationship of HTFGB shear connectors in order to propose equations to predict the load-slip response.

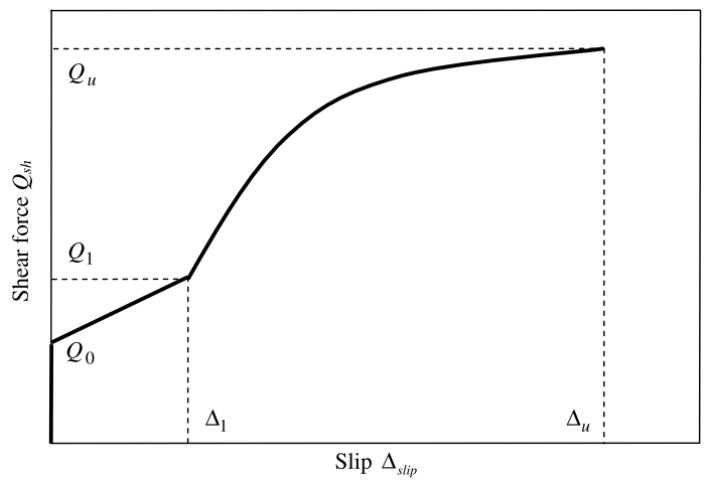

Fig. 13. Design recommendation on the load-slip relationship of HTFGB shear connector in composite beams [21]

Lastly, in other to develop a constructible, effective and durable panel-to-panel connections between the precast concrete slab panels, an interlocking key can be introduced in the precast concrete slab panels as shown in Fig. 14. Interlocking key with a shape of tongue and groove joint in precast concrete will provide a better connection between units of concrete slab. Thus, it will increase the structural performances of the composite beam in terms of load distribution.

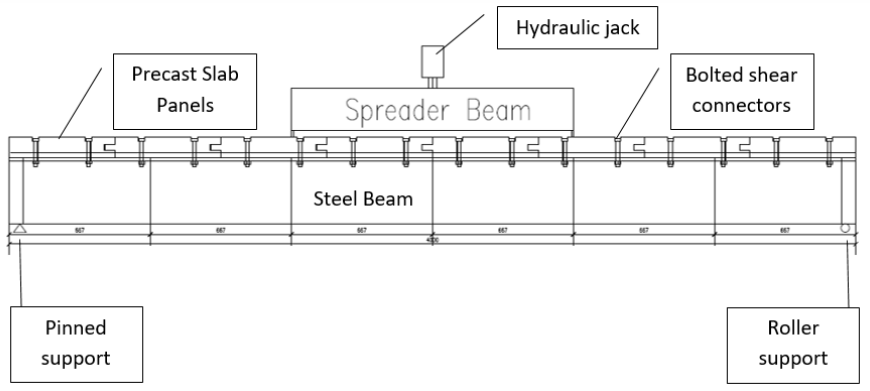

Fig. 14. Proposed configuration of test set-up 
The authors express gratitude to the Universiti Putra Malaysia (UPM) for supporting this work.

\section{References}

1. R. Shamass, \&K. A. Cashell, Behaviour of Composite Beams Made Using High Strength Steel. Structures (2017)

2. A. Ataei, M. A. Bradford, \& X. Liu, Experimental study of composite beams having a precast geopolymer concrete slab and deconstructable bolted shear connectors. Eng. Struct. 114, 1-13 (2015)

3. F. R. Mansour, S. A. Bakar, I. S. Ibrahim \& A. K. Marsono, Flexural performance of a precast concrete slab with steel fiber concrete topping. Constr. Build. Mater. 75, 112-120 (2015)

4. B., Kirkland, P., Kim, B., Uy, \& G., Vasdravellis, Moment - shear - axial force interaction in composite beams (FEM). JCSR 114, 66-76 (2015)

5. EN 1994-1-1. Eurocode 4: Design of composite steel and concrete structures. Part 1-1 General rules and rules for buildings. 1, (2011)

6. British Standards Institution. Structural use of steelwork in building. Part 1, Code of practice for design in simple and continuous construction: hot rolled sections. (British Standards Institution, 1990)

7. S., Adluri, Structural Steel Design Composite Beams. (2005)

8. D., Araújo, de L., Sales, M. W. R., de Paulo, S. M. \& El Debs, A. L. H. de C. Headed steel stud connectors for composite steel beams with precast hollow-core slabs with structural topping. Eng. Struct. 107, 135-150 (2016)

9. Ali Shariati. Various types of shear connectors in composite structures: A review. Int. J. Phys. Sci. 7, 2876-2890 (2012)

10. X., Liu, Bradford, M. A. \& Ataei, A. Flexural performance of innovative sustainable composite steel-concrete beams. Eng. Struct. 130, 282-296 (2017)

11. H. Salehian, \& J.A. O. Barros., Prediction of the Load Carrying Capacity of Elevated Steel Fibre Reinforced Concrete Slabs. Compos. Struct. (2017)

12. M., Pavlović, Z., Marković, M., Veljković, \& Bucrossed D Signevac, D. Bolted shear connectors vs. headed studs behaviour in push-out tests. J. Constr. Steel Res. 88, 134-149 (2013)

13. M.C. Moynihan, \& J. M., Allwood, Viability and performance of demountable composite connectors. J. Constr. Steel Res. 99, 47-56 (2014)

14. M. S. S., Lee, \& Bradford, M. A. Sustainable Composite Beam Behaviour with Deconstructable Bolted Shear Connectors. in Composite Construction in Steel and Concrete VII 445-455 (American Society of Civil Engineers, 2013)

15. G., Kwon, M. D., Engelhardt, \& R. E., Klingner. Experimental behavior of bridge beams retrofitted with postinstalled shear connectors. J. Bridg. Eng. 536-545 (2011)

16. L. N., Dallam, High Strength Bolt Shear Connectors -Pushout Tests. J. Proc. 65, 2017 (1968)

17. W. T., Marshall, H. M., Nelson, \& H. K., Banerjee, An experimental study of the use of high-strength friction grip bolts as shear connectors in composite beams. Struct. Eng. 49, 171-178 (1971)

18. B. G., Rabbat, \& N. W., Hanson, Fatigue tests of bolted connections designed by shear friction. Portl. Cem. Assoc. Res. Dev. Bull. (1973)

19. L., Dallam, \& J., Harpster, Composite beam tests with high-strength bolt shear connectors. Missouri State Highw. Dep. Dep. Civ. Eng. Univ. Missouri-Columbia (1968)

20. Y. T., Chen, Y., Zhao, J. S., West, S. \& Walbridge, Behaviour of steel-precast composite girders with throughbolt shear connectors under static loading. J. Constr. Steel Res. 103, 168-178 (2014)

21. X., Liu, M. A., Bradford, \& M. S. S., Lee, Behavior of High-Strength Friction-Grip Bolted Shear Connectors in Sustainable Composite Beams. J. Struct. Eng. 141, 04014149 (2015)

22. N. M. Hawkins., Strength in Shear and Tension of Cast-in-Place Anchor Bolts. Spec. Publ. 103, 233-256 (1987)

23. G., Kwon, M. D., Engelhardt, \& R. E., Klingner, Behavior of post-installed shear connectors under static and fatigue loading. J. Constr. Steel Res. 66, 532-541 (2010)

24. D. J. Dedic, \& F. W., Klaiber, High-Strength Bolts as Shear Connectors in Rehabilitation Work. Concr. Int. 6, 41-46 (1984)

25. M., Pavlović, M., Spremić, Z., Marković, \& M., Veljković, Headed Shear Studs versus High-Strength Bolts in Prefabricated Composite Decks. in Composite Construction in Steel and Concrete VII 687-702 (American Society of Civil Engineers, 2016)

26. S. W., Pathirana, B., Uy, O., Mirza, \& X. Zhu, Strengthening of existing composite steel-concrete beams utilising 
bolted shear connectors and welded studs. J. Constr. Steel Res. 114, 417-430 (2015)

27. L., Wang, M. D., Webster, \& J. F., Hajjar, Experimental Investigation of Deconstructable Steel-Concrete Shear Connections in Sustainable Composite Beams. in Structures Congress 2017 34-47 (American Society of Civil Engineers, 2017)

28. G., Kwon, M. D., Engelhardt, \& R. E. Klingner, A Case Study of Bridge Strengthening through the Use of PostInstalled Shear Connectors. in Structures Congress 2010 666-675 (American Society of Civil Engineers, 2010)

29. G. Kwon, M. D., Engelhardt, \& R. E., Klingner. Parametric Studies and Preliminary Design Recommendations on the Use of Postinstalled Shear Connectors for Strengthening Noncomposite Steel Bridges. J. Bridg. Eng. 17, 310 317 (2012)

30. G. U. Kwon., Strengthening existing steel bridge girders by the use of post-installed shear connectors. (University of Texas, Austin, 2008)

31. Bursi, O. S., Sun, F. F. \& Postal, S. Non-linear analysis of steelconcrete composite frames with full and partial shear connection subjected to seismic loads. J. Constr. Steel Res. 61, 67-92 (2005)

32. Liu, X., Bradford, M. A., Chen, Q. J. \& Ban, H. Finite element modelling of steel-concrete composite beams with high-strength friction-grip bolt shear connectors. Finite Elem. Anal. Des. 108, 54-65 (2016)

33. Hicks, S. J., Lawson, R. M. \& Lam, D. Design of Composite Beams Using Precast Concrete Slabs. (2004)

34. C., Amadio, C., Bedon,. \& M., Fasan,. Numerical assessment of slab-interaction effects on the behaviour of steelconcrete composite joints. J. Constr. Steel Res. 139, 397-410 (2017)

35. D. J., Oehlers, \& G., Sved, Composite Beams with Limited-Slip-Capacity Shear Connectors. J. Struct. Eng. 121, 932-938 (1995)

36. C., Amadio, C., Bedon, M., Fasan, \& M. R., Pecce, Refined numerical modelling for the structural assessment of steel-concrete composite beam-to-column joints under seismic loads. Eng. Struct. 138, 394-409 (2017)

37. S. W., Pathirana, Uy, B., Mirza, O. \& Zhu, X. Bolted and welded connectors for the rehabilitation of composite beams. J. Constr. Steel Res. 125, 61-73 (2016)

38. X. H., Dai, D., Lam, \& E., Saveri, Effect of Concrete Strength and Stud Collar Size to Shear Capacity of Demountable Shear Connectors. J. Struct. Eng. 4, 04015025 (2015) 